\title{
A study of rate, indications and maternal morbidity associated with cesarean delivery in a tertiary care hospital
}

\author{
Asma Nigar ${ }^{1 *}$, Ausaf Ahmad ${ }^{2}$, Khashia Khan' ${ }^{1}$
}

\begin{abstract}
${ }^{1}$ Department of Obstetrics and Gynecology, Integral Institute of Medical Sciences and Research, Kursi Road, Lucknow, Uttar Pradesh, India

${ }^{2}$ Department of Community Medicine, Integral Institute of Medical Sciences and Research, Kursi Road, Lucknow, Uttar Pradesh, India
\end{abstract}

Received: 08 May 2019

Accepted: 12 June 2019

\section{*Correspondence:}

Dr. Asma Nigar,

E-mail: drasmanigar@gmail.com

Copyright: (c) the author(s), publisher and licensee Medip Academy. This is an open-access article distributed under the terms of the Creative Commons Attribution Non-Commercial License, which permits unrestricted non-commercial use, distribution, and reproduction in any medium, provided the original work is properly cited.

\section{ABSTRACT}

Background: Cesarean section is one of the most commonly performed surgical procedures in obstetrics worldwide. Over the last three decades, a tremendous increase in cesarean section rates has been observed globally, which is a cause for concern as procedure is associated with higher morbidity and mortality compared to vaginal delivery. This study was done to analyze the rate and indications for cesarean section and associated maternal morbidity and mortality.

Methods: This retrospective study was conducted over a period of 6 months from $1^{\text {st }}$ October 2017 to $31^{\text {st }}$ March 2018 in the department of Obstetrics and Gynecology, Integral Institute of Medical Sciences and Research, Lucknow, India. Data of patients who were admitted for delivery in department of Obstetrics and Gynecology in OPD or emergency were recorded. Statistical analysis of various parameters namely, the cesarean section rates, its indications, the patient's morbidity and mortality was done.

Results: The total numbers of women delivered over the study period were 577, out of which 210 patients underwent cesarean sections. The overall cesarean section rate in our study was $36.39 \%$. Previous cesarean section was the leading indication of cesarean section $(31.9 \%)$ followed by arrest of labor (18.1\%), CPD (14.2\%), and fetal distress $(12.9 \%)$. Breech presentation $(5.2 \%)$, failed induction of labor $(4.8 \%)$, pregnancy induced hypertension $(\mathrm{PIH})(3.8 \%)$, oligohydramnios $(3.3 \%)$, obstructed labor $(2.4 \%)$, APH $(1.4 \%)$, multiple pregnancy and BOH accounted for $0.95 \%$ of cesarean sections. $9 \%$ patients had few complications mainly minor wound infection $(2.4 \%)$ and postpartum hemorrhage $(2 \%)$. There was no mortality during this period.

Conclusions: Previous cesarean section has been found to be the main indication for cesarean section. So primary cesarean section should be reduced to decrease the overall cesarean rates. A comprehensive, evidence based approach needs to be introduced to monitor indication of all cesarean section.

Keywords: Cesarean delivery, Cesarean rates, Indications, Maternal morbidity, Previous cesarean primary cesarean section

\section{INTRODUCTION}

Cesarean section is the most common obstetric surgery that was introduced to save lives of women and their newborns from life-threatening pregnancy and childbirth related complications. When medically indicated, a cesarean section can effectively prevent maternal and perinatal mortality and morbidity. However, there is no evidence showing the benefits of cesarean section for women or infants who do not require the procedure. 
Over the past three decades, cesarean section rates have risen substantially worldwide. ${ }^{1}$ According to World Health Organization (WHO) the population based Csection rate should lie between 5 and 15 percent to have an optimal impact. ${ }^{2}$

Both developed and developing countries have shown an increase in the average rate of cesarean section $(27 \%)$ during year 2013. ${ }^{1}$

There are various factors that are responsible for such dramatic increase in cesarean section. Among these, various medical and non medical reasons has been found in researches across the world. ${ }^{3}$

In the developed countries, increase in cesarean delivery has been found to be mainly due to fear of litigation, health insurance system, cesarean section by choice, increased use of electronic fetal cardiac monitoring and increased proportion of breech deliveries by cesarean section.

Several studies conducted across India have shown an alarming rise in the rate of cesarean section deliveries. With increase in institutional deliveries there has also been an increase in cesarean section birth in India. It has been observed that in India, cesarean section rate has increased to $18 \%$ in 2016 as compared to $3 \%$ in 1992.

In a study over a two year period in urban India, the cesarean section rates were reported as $20 \%$ and $38 \%$ in the public and private sectors respectively. A study by Sreevidhya and Sathiyasekeran showed cesarean section rate of $47 \%$ in the private sector. There is also a wide variation in the rates across the different states in the country. ${ }^{4,5}$

The reasons for the alarmingly increased cesarean rates are multifacated. Several studies conclude that many sociodemographic factors are influencing the decision making. Factors other than obstetric causes like, medical, social, ethical, economic and medico legal factors play a very important role in this rising trend of cesarean section. A number of cesarean sections were performed because of personal preferences apart from the clinical indications. $^{6}$

Indications of cesarean section have changed a lot in recent years. It varies as there is no standard classification of indications and there can be multiple and related indications. $^{7}$ Most cesarean sections are currently performed to benefit the fetus and not the mother.

The most common indications of cesarean section include include previous cesarean section, CPD, fetal distress especially its detection by continuous electronic fetal monitoring, arrest of labor, breech presentation, abdominal delivery of growth retarded fetus, malpresentation, increasing body mass, multiple gestation, maternal request and fear of litigation are commonly cited causes. ${ }^{8}$ This study was done to find the rate of cesarean section, indications and associated maternal morbidity and mortality.

\section{METHODS}

This retrospective study was conducted in all patients who underwent cesarean section during 6 months period from $1^{\text {st }}$ October 2017 to $31^{\text {st }}$ March 2018 in the department of obstetrics and gynecology, Integral Institute of Medical Sciences and Research Lucknow, Uttar Pradesh, India.

\section{Inclusion criteria}

- All pregnant women (booked or unbooked), who underwent cesarean section (elective or emergency) during study period was included in this study.

\section{Exclusion criteria}

- Patients who delivered at less than 28 weeks of gestation.

Data of 577 patients were collected in a retrospective manner who delivered in the Obsterics and Gynecology department during the study period. In patients who underwent cesarean sections, their sociodemographic characteristic likes age, parity, booking status, residenceurban/rural. Gestational age at the time of delivery, and whether it was an emergency or planned cesarean section were also recorded. The indications for cesarean section and factors contributing to repeat cesarean sections were recorded separately.

The indications of cesarean section included previous caesarean section, arrest of labor, cephalopelvic disproportion, fetal distress, multiple gestation, malpresentation, and failed induction, fetal and obstetric indications. Foetal indications included oligohydramnios with or without IUGR, big baby $>4 \mathrm{~kg}$ leading to CPD. Obstetric indications are the conditions associated with present pregnancy like placenta previa, abruption, placenta accreta, pre-eclampsia/ eclampsia etc.

Indications for repeat cesarean section were recorded seperately. It included previous 2 more cesarean deliveries,scar tenderness, fetal distress, arrest of labor, refusal to VBAC, malposition, multiple pregnancy, oligohydramnios, $\mathrm{APH}$, and bad obstetric history in association with previous cesarean section. Complications during surgery and post-operative period were also recorded. Data were entered into an excel spreadsheet and results were expressed as mean values and percentages.

Total, primary and repeat caesarean deliveries were calculated. The caesarean rate was calculated as the number of caesarean birth in a year divided by total number of deliveries in that year. 


\section{Statistical analysis}

Statistical analysis was performed using SPSS 16.0 software. Unpaired t-test was used to analyze continuous data. Categorical data was compared using Chi-square test. $\mathrm{P}<0.05$ was taken as statistically significant. Relative risk was calculated for abnormal UA PI, UA RI, UA S/D, MCA PI and cerebral-umbilical PI ratio. Multivariate regression was used to analyze effect of multiple variables.

\section{RESULTS}

Table 1: Demographic analysis of patients who underwent cesarean section.

\begin{tabular}{|lll|}
\hline Variables & $\begin{array}{c}\text { Number of } \\
\text { cesarean }\end{array}$ & $\begin{array}{l}\text { Percentage } \\
(\%)\end{array}$ \\
\hline Age group & & \\
\hline 19 years and below (teens) & 3 & 1.4 \\
\hline 20-25 years & 115 & 54.8 \\
\hline 26-30 years & 66 & 31.4 \\
\hline 31-35 years & 15 & 7.1 \\
\hline Above 35 years & 11 & 5.2 \\
\hline Parity & & \\
\hline Nullipara & 76 & 36.2 \\
\hline Primipara & 81 & 38.6 \\
\hline Multipara (G2-G4) & 53 & 25.3 \\
\hline Antenatal status & & \\
\hline Booked & 56 & 26.7 \\
\hline Unbooked & 154 & 73.3 \\
\hline Place of residence & & \\
\hline Rural & 181 & 86.2 \\
\hline Urban & 29 & 13.8 \\
\hline Religion & & \\
\hline Hindu & 87 & 41.4 \\
\hline Muslim & 123 & 58.6 \\
\hline
\end{tabular}

The sociodemographic characteristics of the respondents are depicted in Table 1. The mean age of the respondents was $25.9 \pm 4.58$ years. Maximum number of cesarean sections were in the age group of 20-25 years $(54.8 \%)$ followed by $31.4 \%$ patients in the age group of $26-30$ years. These two groups constituted $86.2 \%$ of total cesarean sections. Only $5.2 \%$ of the cases belonged to the elderly age group of above 35 years. Maximum no. of cesarean sections was primiparous females $(38.6 \%)$. Out of 210 cesarean deliveries $86.2 \%$ were from rural area. Also, result showed that only $26.7 \%$ of women were booked for antenatal care. Most of the cases belong to Muslim community (Table 1).

Table 2 illustrates that the distribution of elective and emergency cesarean section of the study subjects. There were 210 cases of caesarean section, out of which 44 cases were elective $(21.0 \%)$ and while 166 cases were emergency caesarean sections $(79.0 \%)$. Table clearly defines the prepotency of emergency caesarean sections in the study subjects. Difference in the percentage is about 58\% which shows higher prevalence of emergency caesarean sections (Table 2).

Table 2: Elective vs. emergency cesarean section.

\begin{tabular}{|lll|}
\hline Type of cesarean & $\begin{array}{l}\text { Number of } \\
\text { cesarean }\end{array}$ & Percentage (\%) \\
\hline Elective & 44 & 21.0 \\
\hline Emergency & 166 & 79.0 \\
\hline Total & $\mathbf{2 1 0}$ & $\mathbf{1 0 0 . 0}$ \\
\hline
\end{tabular}

Table 3: Percentage of cesarean section in relation to period of gestation.

\begin{tabular}{|lll|}
\hline Period of gestation & $\begin{array}{l}\text { Number of } \\
\text { cesarean }\end{array}$ & $\begin{array}{l}\text { Percentage } \\
(\%)\end{array}$ \\
\hline Preterm $(<37$ weeks $)$ & 18 & 8.6 \\
\hline Term $(\geq 37$ to $<42$ weeks $)$ & 192 & 91.4 \\
\hline Post term $(\geq 42$ weeks $)$ & 0 & 0.0 \\
\hline Total & $\mathbf{2 1 0}$ & $\mathbf{1 0 0}$ \\
\hline
\end{tabular}

Gestation period of maximum number of cesarean sections was in between greater than 37 weeks and less than 42 weeks (91.4\%) followed by preterm. There were no cases belongs to post term of gestation period (Table $3)$.

Table 4: Indications of cesarean section.

\begin{tabular}{|lll|}
\hline Indication & $\begin{array}{l}\text { Number of } \\
\text { cesarean }\end{array}$ & $\begin{array}{l}\text { Percentage } \\
(\%)\end{array}$ \\
\hline Pre LSCS & 67 & 31.9 \\
\hline Arrest of labor & 38 & 18.1 \\
\hline CPD & 30 & 14.2 \\
\hline Fetal distress & 27 & 12.9 \\
\hline malpresentation & 11 & 5.2 \\
\hline failed induction & 10 & 4.8 \\
\hline PIH & 8 & 3.8 \\
\hline Oligohydramnios & 7 & 3.3 \\
\hline Obstructed labor & 5 & 2.4 \\
\hline APH & 3 & 1.4 \\
\hline Multiple pregnancy & 2 & 0.95 \\
\hline BOH & 2 & 0.95 \\
\hline Total & $\mathbf{2 1 0}$ & $\mathbf{1 0 0 . 0}$ \\
\hline
\end{tabular}

In this study, 210 cases that underwent cesarean section, the most common indication was previous cesarean section 67 (31.9\%), followed by arrest of labor 38 $(18.1 \%)$. Other common causes for cesarean section were CPD (14.2\%), fetal distress (12.9\%), Malpresentations $(5.2 \%)$, and failed induction (4.8\%) (Table 4$)$.

Table 5 shows that among previous cesarean cases, 20 (29.8\%) patients were having previous 2 cesarean sections, 8 (12\%) patients were having previous cesarean section with scar tenderness, 7 (10.4\%) patients were 
having contracted pelvis along with previous cesarean section.

Table 5: Indications contributing to repeat cesarean section.

\begin{tabular}{|lll|}
\hline Indication & $\begin{array}{c}\text { Number } \\
\text { of cases }\end{array}$ & $\begin{array}{l}\text { Percentage } \\
(\%)\end{array}$ \\
\hline >Pre 2 LSCS & 20 & 29.8 \\
\hline Pre 1 LSCS +Scar tenderness & 8 & 12 \\
\hline Pre 1 LSCS +CPD & 7 & 10.4 \\
\hline Pre 1 LSCS +Fetal distress & 7 & 10.4 \\
\hline Pre 1 LSCS +Arrest of labor & 6 & 9 \\
\hline Pre 1 LSCS +Refusal to VBAC & 5 & 7.5 \\
\hline Pre 1 LSCS +PIH & 3 & 4.5 \\
\hline Pre 1 LSCS +Breech & 3 & 4.5 \\
\hline Pre 1 LSCS +Oligohydramnios & 3 & 4.5 \\
\hline Pre 1 LSCS +BOH & 2 & 3 \\
\hline Placenta previa & 2 & 3 \\
\hline Multiple pregnancy & 1 & 1.5 \\
\hline Total & $\mathbf{6 7}$ & $\mathbf{1 0 0 . 0}$ \\
\hline
\end{tabular}

Table 6: Maternal morbidity and mortality.

\begin{tabular}{|lll|}
\hline Complications & $\begin{array}{l}\text { Number of } \\
\text { cesarean }\end{array}$ & $\begin{array}{l}\text { Percentage } \\
(\%)\end{array}$ \\
\hline None & 191 & 91 \\
\hline Wound infection-minor & 5 & 2.4 \\
\hline PPH & 4 & 2 \\
\hline Intraoperative haemorhage & 3 & 1.4 \\
\hline Anaesthetic complication & 3 & 1.4 \\
\hline Abdominal distension & 2 & 0.95 \\
\hline Breathlessness & 1 & 0.47 \\
\hline UTI & 1 & 0.47 \\
\hline Total & $\mathbf{2 1 0}$ & $\mathbf{1 0 0 . 0}$ \\
\hline
\end{tabular}

In $7(10.4 \%)$ cases, there was fetal distress during VBAC trial, $6(9 \%)$ patients underwent cesarean because of arrest of labor. $5(7.5 \%)$ patients refused for VBAC. PIH, oligohydramnios and breech were the indication in $4.5 \%$ of patients. Other less common indications were placenta previa, $\mathrm{BOH}$ and multiple pregnancies.

Table 6 shows the various complications suffered by the respondents during their post natal period. No postpartum morbidity was observed in $191(91 \%)$ of the respondents, whereas $4(2 \%)$ had PPH, $5(2.4 \%)$ patients developed minor wound infection. Intraoperative haemorhage and anaesthetic complications were seen in 3 patients $(1.4 \%)$. Two cases showed complication of abdomen distension. Breathlessness and UTI were seen in one patient that underwent cesarean section (Table 6).

\section{DISCUSSION}

Over the past three decades, the rate of cesarean delivery has increased dramatically. The rates of both primary and repeat cesarean section have been on the rise. ${ }^{9}$
Primary cesarean section usually determines the future obstetric course of any woman and therefore should only be done when it is genuinely indicated. The rate of cesarean section in our study was $36.39 \%$. The high cesarean section rate in our study was observed as this study was conducted in a tertiary care centre. Because of the fact that majority of the pregnant women presented in the emergency were referred cases from PHC (Primary Health Centre), CHC (Community Health Centre), initial trial by dais, and private practitioners. Most of these patients are referred to this teaching hospital who have one or the other risk factors and who already had a trial of labor somewhere else. So the cesarean section rate was obviously high in these high-risk and unbooked cases.

High cesarean rate has also been reported by several studies conducted in India.

Gupta et al found C-Section rate of $31.46 \%$ in their study. ${ }^{10}$

Another study conducted in eastern India has also reported high cesarean section rate of $35.45 \% .^{11}$

Several studies conducted in India have shown wide variation in cesarean section rates at different places. Samdal LJ at al reported lowest cesarean section rates $(9.5 \%)$ in Nepal. ${ }^{12}$ and highest rate $(51.1 \%)$ was reported by $\mathrm{G}$ Singh et al in their study conducted in Haryana. ${ }^{13}$

We observed that mean age of the respondents was $25.9 \pm 4.58$ years in our study, with maximum number 115 $(54.8 \%)$ patients between $20-25$ years age group. Similar result was observed in other studies. ${ }^{14,15}$

In the present study, we observed that out of 210 cesarean deliveries $86.2 \%$ were from rural area. This shows that there is increased awareness among rural women and the improved transport facilities.

In our study $79 \%$ were emergency cesarean section and $21 \%$ were elective cesarean section. It could be because of the fact that our hospital is a tertiary centre located in rural area and majority (73.3\%) patients were unbooked. Patil $\mathrm{P}$ et al in their study also reported $71.1 \%$ emergency cesarean section and $28.9 \%$ elective cesarean section. ${ }^{16}$

Gayathry D et al also reported emergency cesarean section rate of $62.5 \%$ which is higher than elective cesarean section in $37.5 \% .^{17}$

In our study we observed that, among cases that underwent cesarean section, $68.1 \%$ patients underwent primary cesarean section and $67(31.9 \%)$ underwent repeat cesarean section.

The two most common indications of primary cesarean section were arrest of labor (18.1\%) and CPD (14.2\%). Other common causes were fetal distress (12.9\%), malpresentation $(5.2 \%)$, and failed induction $(4.8 \%)$. 
This is comparable to study by Bade $\mathrm{P}$ et al who reported arrest of labor (17.6\%), CPD (11.7\%), fetal distress $(16.6 \%)$ as common indications of primary cesarean section. ${ }^{18}$

On analysis of indications of repeat cesarean section we found that $47(22.4 \%)$ were previous one cesarean section and $20(9.5 \%)$ were previous two cesarean section. Among various factors for cesarean section were scar tenderness (12\%), contracted pelvis (10.4\%), fetal distress $(10.4 \%) .(9 \%)$ patients underwent cesarean because of arrest of labor, $(7.5 \%)$ patients refused for VBAC. PIH, oligohydramnios and breech were the indication in $4.5 \%$ of patients. Other less common indications were placenta previa, $\mathrm{BOH}$ and multiple pregnancies. Patients with previous two or more cesarean section were not given trial of labor.

Lakshmi et al has reported repeat cesarean (43\%) followed by CPD (15\%) as the common indications for cesarean section. ${ }^{19}$

Divyamol $\mathrm{N}$ et al in their study, also reported that the major indications were previous cesarean sections (40.44\%), failure of labor to progress $(22.47 \%)$ and fetal distress $(14.6 \%){ }^{20}$

As we observed in our study and other several studies, that previous cesarean section is the most common indication for cesarean section. So there should be clear, compelling and well supported justification for every cesarean section. VBAC trials with proper selection criteria and proper monitoring can help in reducing the rate of cesarean section. There are evidences which prove VBAC to be safer for women having prior cesarean section as the risk of uterine rupture is low in lower segment cesarean section. ${ }^{21}$

Though cesarean section prevents maternal and neonatal deaths, severe morbidity rate was three times in planned cesarean section compared to planned vaginal delivery. ${ }^{22}$ With the advancement in anaesthetic services, improved surgical techniques, and blood transfusion, the morbidity and mortality of this have come down considerably.

In the present study, no postpartum morbidity was observed in $91 \%$ of the repondents. Minor wound infection $(2.4 \%)$ was the commonest complication followed by atonic PPH (2\%). Among intra-operative complications, intra-operative haemorhage and anaesthetic complications were seen in 3 patients (1.4\%).

In a study by Santhanalakshmi $\mathrm{C}$ et al, the commonest complication was wound infection (38\%). The next common complications were UTI, post-op fever and spinal headache, $20 \%, 19 \%$, and $14.4 \%$ respectively. ${ }^{19}$

Another study by Das RK et al, showed morbidity in $12.02 \%$. Surgical site infection (4.35\%) was the commonest complication followed by atonic $\mathrm{PPH}$ $(2.43 \%))^{11}$

\section{CONCLUSION}

Cesarean delivery due to maternal and fetal indications cannot be deferred. Instead timely performed cesarean section reduces morbidity and mortality. The benefits of the indicated cesarean delivery cannot be denied, but unnecessary cesarean sections must be avoided. We can balance the rate of cesarean by implementing protocol, evidence based medicine, and by judicious use of proper indication for the case.

As repeat cesarean section is a most common cause, reduction of primary cesarean section should be given priority and should only be performed when it is clearly advantageous.

\section{Funding: No funding sources \\ Conflict of interest: None declared \\ Ethical approval: Not required}

\section{REFERENCES}

1. Gibbons L, Belizan JM, Lauer JA, Betran AP, Merialdi M, Althabe F. The global numbers and costs of additionally needed and unnecessary caesarean sections performed per year: overuse as a barrier to universal coverage. World Health Report. 2010;30:1-31.

2. World Health Organization. Appropriate technology for birth. Lancet. 1985;2(8452):436-7.

3. Zhang J, Troendle J, Reddy UM, Laughon SK, Branch DW, Burkman R, et al. Contemporary cesarean delivery practice in the United States. Am J Obstet Gynecol. 2010;203:326.e1-e10.

4. Arjun G, Rajasri S, Balakrishnan S. The management of labor: Arulkumaran S, Gita Arjun, Leonie K Penna. Cesarean section procedure and technique. $3^{\text {rd }}$ Ed. India universities press. 2011:248-65.

5. Sreevidya S, Sathiyasekaran BW. High cesarean rates in Madras (India): a population based cross sectional study. $\mathrm{Br} \quad \mathrm{J}$ Obstet Gynecol. 2003;110(2):106-11.

6. Mishra US, Ramanathan M. Delivery-related complications and determinants of caesarean section rates in India. Health Policy Plan. 2002;17(1):90-8.

7. Torloni MR, Betran AP, Souza JP, Widmer M, Allen T, Gulmezoglu M, et al. Classification for caesarean section: a systemtic review. PLoS One. 2011;6:e1456.

8. Tollanes MC. Increased rate of Caesarean sections causes and consequences. Tidsskr Nor Laegeforen. 2009;129(13):1329-31.

9. Barber EL, Lundsberg LS, Belanger K. Indications contributing to the increasing caesarean delivery rate. Obstet Gynecol. 2011;118(1):29-38.

10. Gupta M, Garg V. The rate and indications of caesarean section in a tertiary care hospital at Jaipur, 
India. Int J Reprod Contracept Obstet Gynecol. 2017;6(5):1786-92.

11. Das RK, Subudhi KT, Mohanty RK. The rate and indication of caesarean section in a tertiary care teaching hospital eastern India. Int $\mathbf{J}$ Contemp Pediatr. 2018;5(5):1733-9.

12. Samdal LJ, Steinsvik KR, Pun P, Dani P, Roald B, Stray-Pedersen B, et al. Indications for Cesarean Sections in Rural Nepal. J Obstet Gynaecol India. 2016;66(1):284-8.

13. Signh G, Gupta ED. Rising incidence of caesarean section in rural area in Haryana, India: a retrospective analysis. Internet $\mathrm{J}$ Gynecol Obetet. 2013;17(2):1-5.

14. Jawa A, Garg S, Tater A, Sharma U. Indications and rates of lower segment caesarean section at tertiary care hospital-an analytical study. Int J Reprod Contracept Obstet Gynecol. 2016;5:3466-9.

15. Sarma P, Boro RC, Acharjee PS. An analysis of indications of caesarean sections at Tezpur medical college and hospital, Tezpur (a government hospital). Int J Reprod Contracept Obstet Gynecol. 2016;5:1364-7.

16. Patil P, Bhardwaj M, Sharma P, Chandrakar G. Changing trends in indication of cesarean section in a tertiary care centre of Central India. Int J Reprod Contracept Obstet Gynecol. 2017;6(7):2829-35.

17. Dasari G, Guthi VR, Bele S, Vivekannada A. A study of maternal morbidity associated with caesarean delivery in tertiary care hospital. Int J Com Med Public Health. 2017;4(5):543.
18. Bade P, Kendre V, Jadhav Y, Wadagale A. An analysis of indications for caesarean section at government medical college, Latur. Intern J Recent Trends Sci Technol. 2014;11(1):6-8.

19. Santhanalakshmi C, Gnanasekaran V, Chakravarthyet AR. A retrospective analysis of cesarean section in a tertiary care hospital. Int J Sci Res. 2013;4(9):2097-9.

20. Divyamol N, Raphael L, Koshy N. Caesarean section rate and its determinants in a rural area of South India. Int $\mathbf{J}$ Community Med Public Health. 2016;3:2836-40.

21. Spong CY, Lanndon MB. Risk of uterine Rupture and adverse perinatal outcome at term after caesarean delivery. Obstet Gynaecol. 2007;110(4):801-7.

22. Liu S, Liston RM, Joseph KS, Heaman M, Sauve R, Kramer MS, et al. Maternal mortality and severe morbidity associated with low-risk planned cesarean delivery versus planned vaginal delivery at term. CMAJ. 2007;176(4):455-60.

Cite this article as: Nigar A, Ahmad A, Khan K. A study of rate, indications and maternal morbidity associated with cesarean delivery in a tertiary care hospital. Int J Reprod Contracept Obstet Gynecol 2019;8:2810-5. 